\title{
STUDI POTENSI PEMBANGKIT LISTRIK TENAGA GELOMBANG LAUT DENGAN METODA OSCILATING WATER COLUMN DI PERAIRAN KENDARI INDONESIA
}

\author{
Faulincia ${ }^{1, a}$ \\ 1Jurusan Teknik Elektro Fakultas Teknik Sekolah Tinggi Teknik PLN Jakarta, Indonesia \\ a faulincia@gmail.com
}

\begin{abstract}
Abstrak.
Merujuk pada Undang-undang Nomor 30 Tahun 2007 tentang Energi, perkembangan teknik konversi energi listrik dengan menggunakan sumber energi alternative menjadi menarik untuk diikuti selama beberapa tahun terakhir ini. Makalah ini membahas mengenai analsis perhitungan potensi daya konversi tenaga gelombang laut dengan menggunakan sistem Oscilating Water Column (OWC) di wilayah kelautan di Indonesia. Sistem ini dipilih karena memiliki banyak keuntungan dibanding sistem lainnya dan sesuai dengan wilayah kelautan dan pantai Indonesia. Dari hasil perhitungan daya didapatkan daya terkecil yang dapat dihasilkan adalah sebesar 348.5838 Watt sementara daya terbesar yang dapat dihasilkan adalah sebesar 623291.4 Watt Penerapan sistem oscillating water column di wilayah perairan Kendari dengan efisiensi 11,971\%.

Kata kunci. oscillating water column (OWC), energi gelombang laut, energi listrik, potensi daya, panjang gelombang

Abstract.

Referring to Law Number 30 of 2007 concerning Energy, the development of techniques the conversion of electrical energy by using alternative energy sources is interesting for followed for the past few years. This paper discusses calculation analysis power potential of ocean wave conversion using the Oscilating Water system Column $(O W C)$ in the marine area of Indonesia. This system was chosen because it has many advantages compared to other systems and in accordance with the marine and coastal areas of Indonesia. From the calculation of power, the smallest power that can be produced is equal to 348.5838 Watts while the biggest power that can be produced is 623291.4 Watts The application of the oscillating water column system in Kendari waters with an efficiency of $11.971 \%$.
\end{abstract}

Keywords. oscillating water column $(O W C)$, ocean wave energy, electrical energy, power potential, wavelength

\section{PENDAHULUAN}

Dibutuhkan suatu studi yang mendalam mengenai penggunaan energi alternatiif terbarukan dan ramah lingkungan. Indonesia sebagai Negara maritime mempunyai wilayah lautan sebesar 2/3 dari seluruh wilayah Indonesia, mendekati 70\% dari luas keseluruhan Negara Indonesia. Wilayah lautan yang luas tentunya mempunyai potensi yang besar pula, demikian juga energi gelombang lautnya. Sangat penting memilih lokasi yang secara topografi memungkinkan akumulasi energi. Pada penulisan seminar ini memilih wilayah perairan Kendari, karena berdasarkan data yang diperoleh dari Badan Meteorologi Klimatologi dan Geofisika, wilayah perairan Kendari paling berpotensi untuk tinggi gelombang mencapai $4 \mathrm{~m}$. Dimana Gelombang dengan ketinggian $>2.0$ - 3.0 di perkirakan terjadi di Perairan Baubau, Perairan Kep. Wakatobi, Perairan Manuai Kendari, Laut Banda Timur Sultra, Laut Seram Bagian Timur, Perairan Selatan Ambon, Laut Banda Bagian Utara, Laut Banda Bagian Selatan, Perairan Kep. Kai, Perairan Kep. Aru, Perairan Kep. Babar, Perairan Kep. Sermata-Kep. Leti. Gelombang dengan ketinggian >3.0 - 4.0 di perkirakan terjadi di Perairan Kep. Tanimbar, Laut Arafuru Bagian Barat, Laut Arafuru bagian Tengah Pada analisa potensi 
gelombang laut menjadi energi listrik digunakan metode kolom air berosilasi atau biasa disebut oscilatting water column (owc).

\section{Studi Pustaka}

\begin{tabular}{|l|l|l|}
\hline \multicolumn{1}{|c|}{ Penulis } & \multicolumn{1}{|c|}{ Judul Makalah } & \multicolumn{1}{c|}{ Keterkaitan Dengan Penelitian } \\
\hline $\begin{array}{l}\text { Indah Luh } \\
\text { Sepdyanuri }\end{array}$ & $\begin{array}{l}\text { Konversi Energi Sistem } \\
\text { Pembangkit Listrik tenaga } \\
\text { Gelombang Laut }\end{array}$ & Meneliti Bagian Konversi Mesin \\
\hline Abdul Rauf Taufik & $\begin{array}{l}\text { Pembangkit Listrik Tenaga } \\
\text { Gelombang Laut (Generator } \\
\text { Induksi) }\end{array}$ & $\begin{array}{l}\text { Pembangkit Listrik Tenaga } \\
\text { Gelombang Laut Dengan OWC }\end{array}$ \\
\hline Syamsul Arifin & $\begin{array}{l}\text { Makalah Teknik Konversi Energi } \\
\text { Teknik Konversi Energi } \\
\text { Gelombang Menjadi Energi } \\
\text { Listrik }\end{array}$ & $\begin{array}{l}\text { Teknik Konversi Energi laut } \\
\text { Menjadi Energi Listrik dengan } \\
\text { Metode Oscillating Water Column }\end{array}$ \\
\hline $\begin{array}{l}\text { Kadek Fendy } \\
\text { Sutrisna }\end{array}$ & $\begin{array}{l}\text { Pembangkit Listrik Masa Depan } \\
\text { Indonesia }\end{array}$ & $\begin{array}{l}\text { Laboratorium Konversi Energi } \\
\text { Listrik, Sekolah Teknik Dan } \\
\text { Informatika, Institut Teknologi } \\
\text { Bandung }\end{array}$ \\
\hline
\end{tabular}

\section{METODOLOGI PENELITIAN}

Untuk menunjang hasil penulisan yang diinginkan, maka dilakukan suatu pendekatan studi dengan melakukan kegiatan dibawah ini :

1. Membandingkan semua data tinggi, periode, panjang gelombang bersumber Badan Meteorologi Klimatologi dan Geofisika sehingga didapatkan energi laut yang di konversi menjadi energi listrik yang optimal.

2. Mengunakan metode yaitu metode Oscillating Water Column

\section{HASIL, PEMBAHASAN DAN ANALISA}

1. Data Hidro-Oseanografi

Data hidro-oseanografi meliputi data gelombang laut di wilayah perairan Kendari. Data ini sangat menentukan perkiraan awal besarnya daya yang dapat dibangkitkan oleh PLTGL sistem Oscillating Water Column (OWC). Data tinggi gelombang laut di wilayah peraiaran Kendari ini diperoleh melalui badan meteorologi klimatologi dan geofisika pada tanggal 24 Mei 2015 dapat dilihat pada tabel 1 bab 3 .

2. Panjang dan Kecepatan Gelombang Laut

Panjang dan Kecepatan Gelombang laut dipengaruhi oleh periode datangnya gelombang. Periode datangnya gelombang dapat dihitung dengan menggunakan rumus yang disarankan oleh Kim Nielsen [9], yaitu :

$$
\mathrm{T}=3.55 \sqrt{H}
$$

Dari data tinggi signifikan rata-rata gelombang laut, maka kita dapat mengetahui periode masing-masing daerah, dengan contoh perhitungan periode gelombang datang pada perairan kondisi minimum, yaitu:

$$
\mathrm{T}=3.55 \sqrt{0.1}=1.123
$$


Tabel 4.1 Hasil perhitungan Periode Gelombang Datang

\begin{tabular}{|l|l|c|c|c|c|}
\hline \multirow{2}{*}{ No } & \multicolumn{1}{|c|}{ NAMA WILAYAH PERAIRAN } & \multicolumn{2}{c|}{$\begin{array}{c}\text { Tinggi Gelombang } \\
\text { Signifikan Rata-Rata } \\
\text { (meter) }\end{array}$} & $\begin{array}{c}\text { Periode Gelombang } \\
\text { Datang (detik) }\end{array}$ \\
\cline { 3 - 6 } & & Min & Max & Min & Max \\
\hline N.1 & PERAIRAN BAUBAU & 0,1 & 1.5 & 1.123 & 4.35 \\
\hline N.2 & PERAIRAN KEP. WAKATOBI & 0,1 & 1.5 & 1.123 & 4.35 \\
\hline N.3 & PERAIRAN MANUI-KENDARI & 0,1 & 1.3 & 1.123 & 4.05 \\
\hline N.4 & LAUT BANDA TIMUR SULTRA & 0,1 & 1.5 & 1.123 & 4.35 \\
\hline N.5 & TELUK TOLO & 0,1 & 1.3 & 1.123 & 4.05 \\
\hline N.6 & PERAIRAN KEP. BANGGAI & 0,1 & 1.3 & 1.123 & 4.05 \\
\hline N.7 & PERAIRAN KEP. SULA & 0,1 & 1.3 & 1.123 & 4.05 \\
\hline N.8 & LAUT SERAM BAGIAN BARAT & 0,1 & 1.3 & 1.123 & 4.05 \\
\hline N.9 & LAUT SERAM BAGIAN TIMUR & 0,1 & 1.5 & 1.123 & 4.35 \\
\hline N.10 & PERAIRAN SELATAN AMBON & 0,1 & 1.5 & 1.123 & 4.35 \\
\hline N.11 & LAUT BANDA BAGIAN UTARA & 0,1 & 1.5 & 1.123 & 4.35 \\
\hline N.12 & LAUT BANDA BAGIAN SELATAN & 0,1 & 2.0 & 1.123 & 5.02 \\
\hline N.13 & PERAIRAN KEP. KAI & 0,1 & 2.0 & 1.123 & 5.02 \\
\hline N.14 & PERAIRAN KEP. ARU & 0,1 & 2.0 & 1.123 & 5.02 \\
\hline N.15 & PERAIRAN KEP. TANIMBAR & 0,1 & 2.0 & 1.123 & 5.02 \\
\hline N.16 & PERAIRAN KEP. BABAR & 0,1 & 2.0 & 1.123 & 5.02 \\
\hline N.17 & PERAIRAN KEP. SERMATA - & 0,1 & 2.0 & 1.123 & 5.02 \\
\hline N.18 & KLAEPUT. LAETRAI FURU BAGIAN & 0,1 & 2.5 & 1.123 & 5.6 \\
\hline N.19 & LARAT ARAFURU BAGIAN TENGAH & 0,1 & 2.5 & 1.123 & 5.6 \\
\hline & & & & & \\
\hline
\end{tabular}

Dengan mengetahui prakiraan periode datangnya gelombang pada daerah perairan pantai Indonesia, maka dapat di hitung besar panjang dan kecepatan gelombangnya berdasarkan persamaan yang disarankan oleh David Ross [10] sebagai berikut :

$$
\lambda=5.12 \mathrm{~T}^{2}
$$

Contoh perhitungan panjang gelombang datang perairan Baubau :

$$
\lambda=5.12 \mathrm{~T}^{2}=5.12(1.123)^{2}=6.45 \mathrm{~m}
$$

\begin{tabular}{|c|c|c|c|c|c|}
\hline \multirow[t]{2}{*}{ NO } & \multirow[t]{2}{*}{ NAMA WILAYAH PERAIRAN } & \multicolumn{2}{|c|}{$\begin{array}{c}\text { Periode Gelombang } \\
\text { Datang } \\
\text { (detik) }\end{array}$} & \multicolumn{2}{|c|}{$\begin{array}{c}\text { Panjang Gelombang } \\
\text { Datang (meter) }\end{array}$} \\
\hline & & Min & Max & Min & Max \\
\hline N.1 & PERAIRAN BAUBAU & 1.123 & 4.35 & 6.45698 & 96.8832 \\
\hline N.2 & PERAIRAN KEP. WAKATOBI & 1.123 & 4.35 & 6.45698 & 96.8832 \\
\hline N.3 & PERAIRAN MANUI-KENDARI & 1.123 & 4.05 & 6.45698 & 83.9808 \\
\hline N.4 & LAUT BANDA TIMUR SULTRA & 1.123 & 4.35 & 6.45698 & 96.8832 \\
\hline N.5 & TELUK TOLO & 1.123 & 4.05 & 6.45698 & 83.9808 \\
\hline N.6 & PERAIRAN KEP. BANGGAI & 1.123 & 4.05 & 6.45698 & 83.9808 \\
\hline N.7 & PERAIRAN KEP. SULA & 1.123 & 4.05 & 6.45698 & 83.9808 \\
\hline
\end{tabular}

Tabel 4.2 Hasil Perhitungan Panjang Gelombang Datang 


\begin{tabular}{|l|l|l|l|l|l|}
\hline N.8 & LAUT SERAM BAGIAN BARAT & 1.123 & 4.05 & 6.45698 & 83.9808 \\
\hline N.9 & LAUT SERAM BAGIAN TIMUR & 1.123 & 4.35 & 6.45698 & 96.8832 \\
\hline N.10 & PERAIRAN SELATAN AMBON & 1.123 & 4.35 & 6.45698 & 96.8832 \\
\hline N.11 & LAUT BANDA BAGIAN UTARA & 1.123 & 4.35 & 6.45698 & 96.8832 \\
\hline N.12 & LAUT BANDA BAGIAN SELATAN & 1.123 & 5.02 & 6.45698 & 129.026 \\
\hline N.13 & PERAIRAN KEP. KAI & 1.123 & 5.02 & 6.45698 & 129.026 \\
\hline N.14 & PERAIRAN KEP. ARU & 1.123 & 5.02 & 6.45698 & 129.026 \\
\hline N.15 & PERAIRAN KEP. TANIMBAR & 1.123 & 5.02 & 6.45698 & 129.026 \\
\hline N.16 & PERAIRAN KEP. BABAR & 1.123 & 5.02 & 6.45698 & 129.026 \\
\hline N.17 & $\begin{array}{l}\text { PERAIRAN KEP. SERMATA - KEP. } \\
\text { LETI }\end{array}$ & 1.123 & 5.02 & & \\
\hline N.18 & LAUT ARAFURU BAGIAN BARAT & 1.123 & 5.6 & 6.45698 & 160.5632 \\
\hline N.19 & $\begin{array}{l}\text { LAUT ARAFURU BAGIAN } \\
\text { TENGAH }\end{array}$ & & 5.123 & 6.45698 & 160.5632 \\
\hline
\end{tabular}

Maka kecepatan gelombang datang dapat diperoleh dengan menggunakan rumus

$$
\mathrm{V}=\frac{\lambda}{\mathrm{T}}
$$

Berikut contoh perhitungan kecepatan gelombang datang pada perairan Baubau

$$
\mathrm{V}=\frac{\lambda}{\mathrm{T}}=\frac{\lambda}{\mathrm{T}}=\frac{6.45}{1.13}=5.74976 \mathrm{~m} / \mathrm{s}
$$

Tabel 4.3 Hasil Perhitungan Kecepatan Gelombang Datang

\begin{tabular}{|l|l|c|c|c|c|c|c|}
\hline \multirow{2}{*}{ No } & \multicolumn{1}{|c|}{$\begin{array}{c}\text { NAMA WILAYAH } \\
\text { PERAIRAN }\end{array}$} & \multicolumn{2}{|c|}{$\begin{array}{c}\text { Periode } \\
\text { Gelombang } \\
\text { Datang } \\
\text { (detik) }\end{array}$} & \multicolumn{2}{|c|}{$\begin{array}{c}\text { Panjang } \\
\text { Gelombang } \\
\text { Datang (meter) }\end{array}$} & \multicolumn{2}{c|}{$\begin{array}{c}\text { Kecepatan } \\
\text { Gelombang } \\
\text { Datang } \\
\text { (meter/detik) }\end{array}$} \\
\cline { 3 - 8 } Min & \multicolumn{1}{|c|}{ Max } & Min & Max & Min & Max \\
\hline N.1 & PERAIRAN BAUBAU & 1.123 & 4.35 & 6.45698 & 96.8832 & 5.74976 & 22.272 \\
\hline N.2 & $\begin{array}{l}\text { PERAIRAN KEP. } \\
\text { WAKATOBI }\end{array}$ & 1.123 & 4.35 & 6.45698 & 96.8832 & 5.74976 & 22.272 \\
\hline N.3 & $\begin{array}{l}\text { PERAIRAN } \\
\text { MANUIKENDARI }\end{array}$ & 1.123 & 4.05 & 6.45698 & 83.9808 & 5.74976 & 20.736 \\
\hline N.4 & $\begin{array}{l}\text { LAUT BANDA TIMUR } \\
\text { SULTRA }\end{array}$ & 1.123 & 4.35 & 6.45698 & 96.8832 & 5.74976 & 22.272 \\
\hline N.5 & TELUK TOLO & 1.123 & 4.05 & 6.45698 & 83.9808 & 5.74976 & 20.736 \\
\hline N.6 & $\begin{array}{l}\text { PERAIRAN KEP. } \\
\text { BANGGAI }\end{array}$ & 1.123 & 4.05 & 6.45698 & 83.9808 & 5.74976 & 20.736 \\
\hline N.7 & PERAIRAN KEP. SULA & 1.123 & 4.05 & 6.45698 & 83.9808 & 5.74976 & 20.736 \\
\hline N.8 & $\begin{array}{l}\text { LAUT SERAM BAGIAN } \\
\text { BARAT }\end{array}$ & 1.123 & 4.05 & 6.45698 & 83.9808 & 5.74976 & 20.736 \\
\hline N.9 & $\begin{array}{l}\text { LAUT SERAM BAGIAN } \\
\text { TIMUR }\end{array}$ & 1.123 & 4.35 & 6.45698 & 96.8832 & 5.74976 & 22.272 \\
\hline N.10 & $\begin{array}{l}\text { PERAIRAN SELATAN } \\
\text { AMBON }\end{array}$ & 1.123 & 4.35 & 6.45698 & 96.8832 & 5.74976 & 22.272 \\
\hline N.11 & LAUT BANDA BAGIAN & 1.123 & 4.35 & 6.45698 & 96.8832 & 5.74976 & 22.272 \\
\hline
\end{tabular}




\begin{tabular}{|l|l|c|c|c|c|c|c|}
\hline & UTARA & & & & & & \\
\hline N.12 & $\begin{array}{l}\text { LAUT BANDA BAGIAN } \\
\text { SELATAN }\end{array}$ & 1.123 & 5.02 & 6.45698 & 129.026 & 5.74976 & 25.7024 \\
\hline N.13 & PERAIRAN KEP. KAI & 1.123 & 5.02 & 6.45698 & 129.026 & 5.74976 & 25.7024 \\
\hline N.14 & PERAIRAN KEP. ARU & 1.123 & 5.02 & 6.45698 & 129.026 & 5.74976 & 25.7024 \\
\hline N.15 & $\begin{array}{l}\text { PERAIRAN KEP. } \\
\text { TANIMBAR }\end{array}$ & 1.123 & 5.02 & 6.45698 & 129.026 & 5.74976 & 25.7024 \\
\hline N.16 & PERAIRAN KEP. BABAR & 1.123 & 5.02 & 6.45698 & 129.026 & 5.74976 & 25.7024 \\
\hline N.17 & $\begin{array}{l}\text { PERAIRAN KEP. } \\
\text { SERMATA - KEP. LETI }\end{array}$ & 1.123 & 5.02 & 6.45698 & 129.026 & 5.74976 & 25.7024 \\
\hline N.18 & $\begin{array}{l}\text { LAUT ARAFURU BAGIAN } \\
\text { BARAT }\end{array}$ & 1.123 & 5.6 & 6.45698 & $\begin{array}{c}160.563 \\
2\end{array}$ & 5.74976 & 28.672 \\
\hline N.19 & $\begin{array}{l}\text { LAUT ARAFURU BAGIAN } \\
\text { TENGAH }\end{array}$ & 1.123 & 5.6 & 6.45698 & $\begin{array}{c}160.563 \\
2\end{array}$ & 5.74976 & 28.672 \\
\hline
\end{tabular}

Keterangan :

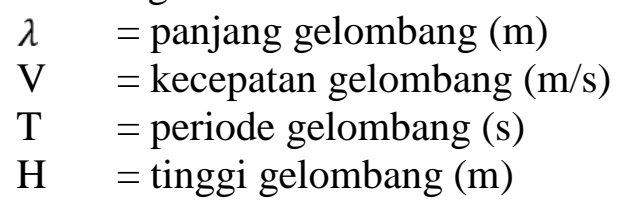

\section{Analisis Perhitungan Energi Gelombang Laut :}

Potensi energi gelombang laut dengan lebar chamber 2,4 $\mathrm{m}$ (berdasarkan protipe yang telah ada), $\rho$ air laut $1030 \mathrm{Kg} / \mathrm{m}^{3}$, dan gravitasi bumi $9,81 \mathrm{~m} / \mathrm{s}^{2}$, persamaan untuk menghitung energi gelombang laut yang dihasilkan cukup dengan menghitung energi potensial saja. Karena dilihat dari prototype yang ada, pergerakan gelombang laut yang menghasilkan energi pada sistem ini merupakan energi potensial atau naik turun gelombangnya saja. Sementara untuk gerakan gelombang laut yang maju mundur tidak menghasilkan energi maka persamaan 3.3 tidak digunakan, tetapi menggunakan persamaan 2.5 :

$$
\mathrm{Ew}=\frac{1}{4} \cdot \mathrm{w} \cdot \rho \cdot g \cdot \mathrm{a}^{2} \cdot \lambda(J)
$$

Contoh perhitungan pada pantai perairan Bau bau pada

$$
\begin{gathered}
\mathrm{Ew}=\frac{1}{4} \cdot \mathrm{w} \cdot \rho \cdot \mathrm{g} \cdot \mathrm{a}^{2} \cdot \lambda \\
=\frac{1}{4} \cdot 2 \cdot 4 \mathrm{~m} \cdot 1030 \mathrm{Kg} / \mathrm{m}^{3} \cdot 9.81 \mathrm{~m} / \mathrm{s}^{2} \cdot 0.1^{2} \cdot 6.54 \mathrm{~m} \\
=391.4596072 \mathrm{~J}
\end{gathered}
$$

Tabel 4.4 Hasil Perhitungan Potensi Energi Gelombang Laut

\begin{tabular}{|l|l|c|c|}
\hline NO & \multicolumn{1}{|c|}{ NAMA WILAYAH PERAIRAN } & $\begin{array}{c}\text { Potensi Energi } \\
\text { Gelombang Kondisi } \\
(\mathbf{J})\end{array}$ & $\begin{array}{c}\text { Potensi Energi } \\
\text { Gelombang Kondisi } \\
(\mathbf{J})\end{array}$ \\
\hline N.1 & PERAIRAN BAUBAU & 391.4596072 & 1321564.839 \\
\hline N.2 & PERAIRAN KEP. WAKATOBI & 391.4596072 & 1321564.839 \\
\hline N.3 & PERAIRAN MANUI-KENDARI & 391.4596072 & 860447.1382 \\
\hline N.4 & LAUT BANDA TIMUR SULTRA & 391.4596072 & 1321564.839 \\
\hline N.5 & TELUK TOLO & 391.4596072 & 860447.1382 \\
\hline N.6 & PERAIRAN KEP. BANGGAI & 391.4596072 & 860447.1382 \\
\hline N.7 & PERAIRAN KEP. SULA & 391.4596072 & 860447.1382 \\
\hline N.8 & LAUT SERAM BAGIAN BARAT & 391.4596072 & 860447.1382 \\
\hline N.9 & LAUT SERAM BAGIAN TIMUR & 391.4596072 & 1321564.839 \\
\hline
\end{tabular}




\begin{tabular}{|l|l|l|l|}
\hline N.10 & PERAIRAN SELATAN AMBON & 391.4596072 & 1321564.839 \\
\hline N.11 & LAUT BANDA BAGIAN UTARA & 391.4596072 & 1321564.839 \\
\hline N.12 & LAUT BANDA BAGIAN SELATAN & 391.4596072 & 3128922.952 \\
\hline N.13 & PERAIRAN KEP. KAI & 391.4596072 & 3128922.952 \\
\hline N.14 & PERAIRAN KEP. ARU & 391.4596072 & 3128922.952 \\
\hline N.15 & PERAIRAN KEP. TANIMBAR & 391.4596072 & 3128922.952 \\
\hline N.16 & PERAIRAN KEP. BABAR & 391.4596072 & 3128922.952 \\
\hline N.17 & $\begin{array}{l}\text { PERAIRAN KEP. SERMATA - KEP. } \\
\text { LETI }\end{array}$ & 391.4596072 & 3128922.952 \\
\hline N.18 & LAUT ARAFURU BAGIAN BARAT & 391.4596072 & 6083920.282 \\
\hline N.19 & LAUT ARAFURU BAGIAN TENGAH & 391.4596072 & 6083920.282 \\
\hline
\end{tabular}

Daya yang dapat dibangkitkan dari energi gelombang laut daerah perairan pantai di Indonesia dapat diperoleh dengan menggn persamaan 3.5 :

$$
\begin{aligned}
\mathrm{Pw} & =\frac{\mathrm{Ew}}{\mathrm{T}} \\
& =\frac{391.4596072}{1.12}=348.5838 \mathrm{Watt}
\end{aligned}
$$

\begin{tabular}{|c|c|c|c|c|c|c|c|}
\hline \multirow[t]{2}{*}{ NO } & \multirow[t]{2}{*}{$\begin{array}{c}\text { NAMA } \\
\text { WILAYAH } \\
\text { PERAIRAN }\end{array}$} & \multicolumn{2}{|c|}{$\begin{array}{c}\text { Periode } \\
\text { Gelombang } \\
\text { Datang } \\
\text { (detik) }\end{array}$} & \multicolumn{2}{|c|}{$\begin{array}{l}\text { Potensi Energi } \\
\text { Gelombang Kondisi (J) }\end{array}$} & \multicolumn{2}{|c|}{ Daya (Watt) } \\
\hline & & Min & Max & Min & Max & Min & Max \\
\hline N.1 & $\begin{array}{l}\text { PERAIRAN } \\
\text { BAUBAU }\end{array}$ & 1.123 & 4.35 & 391.4596072 & 1321564.839 & 348.5838 & 303808 \\
\hline N.2 & $\begin{array}{l}\text { PERAIRAN } \\
\text { KEP. } \\
\text { WAKATOBI }\end{array}$ & 1.123 & 4.35 & 391.4596072 & 1321564.839 & 348.5838 & 3303808 \\
\hline N.3 & $\begin{array}{l}\text { PERAIRAN } \\
\text { MANUI } \\
\text { KENDARI }\end{array}$ & 1.123 & 4.05 & 391.4596072 & 860447.1382 & 348.5838 & 212456.1 \\
\hline N.4 & $\begin{array}{l}\text { LAUT } \\
\text { BANDA } \\
\text { TIMUR } \\
\text { SULTRA }\end{array}$ & 1.123 & 4.35 & 391.4596072 & 1321564.839 & 348.5838 & 303808 \\
\hline N.5 & TELUK TOLO & 1.123 & 4.05 & 391.4596072 & 860447.1382 & 348.5838 & 212456.1 \\
\hline N.6 & $\begin{array}{l}\text { PERAIRAN } \\
\text { KEP. } \\
\text { BANGGAI }\end{array}$ & 1.123 & 4.05 & 391.4596072 & 860447.1382 & 348.5838 & 212456.1 \\
\hline N.7 & $\begin{array}{l}\text { PERAIRAN } \\
\text { KEP. SULA }\end{array}$ & 1.123 & 4.05 & 391.4596072 & 860447.1382 & 348.5838 & 212456.1 \\
\hline N.8 & $\begin{array}{l}\text { LAUT } \\
\text { SERAM } \\
\text { BAGIAN } \\
\text { BARAT } \\
\end{array}$ & 1.123 & 4.05 & 391.4596072 & 860447.1382 & 348.5838 & 212456.1 \\
\hline
\end{tabular}

Tabel 4.5 Hasil Perhitungan Daya Yang Dapat Dibangkitkan 


\begin{tabular}{|c|c|c|c|c|c|c|c|}
\hline N.9 & $\begin{array}{l}\text { LAUT } \\
\text { SERAM } \\
\text { BAGIAN } \\
\text { TIMUR }\end{array}$ & 1.123 & 4.35 & 391.4596072 & 1321564.839 & 348.5838 & 303808 \\
\hline N.10 & $\begin{array}{l}\text { PERAIRAN } \\
\text { SELATAN } \\
\text { AMBON }\end{array}$ & 1.123 & 4.35 & 391.4596072 & 1321564.839 & 348.5838 & 303808 \\
\hline N.11 & $\begin{array}{l}\text { LAUT } \\
\text { BANDA } \\
\text { BAGIAN } \\
\text { UTARA }\end{array}$ & 1.123 & 4.35 & 391.4596072 & 1321564.839 & 348.5838 & 303808 \\
\hline N.12 & $\begin{array}{l}\text { LAUT } \\
\text { BANDA } \\
\text { BAGIAN } \\
\text { SELATAN }\end{array}$ & 1.123 & 5.02 & 391.4596072 & 3128922.952 & 348.5838 & 623291.4 \\
\hline N.13 & $\begin{array}{l}\text { PERAIRAN } \\
\text { KEP. KAI }\end{array}$ & 1.123 & 5.02 & 391.4596072 & 3128922.952 & 348.5838 & 623291.4 \\
\hline N.14 & $\begin{array}{l}\text { PERAIRAN } \\
\text { KEP. ARU }\end{array}$ & 1.123 & 5.02 & 391.4596072 & 3128922.952 & 348.5838 & 623291.4 \\
\hline N.15 & $\begin{array}{l}\text { PERAIRAN } \\
\text { KEP. } \\
\text { TANIMBAR }\end{array}$ & 1.123 & 5.02 & 391.4596072 & 3128922.952 & 348.5838 & 623291.4 \\
\hline N.16 & $\begin{array}{l}\text { PERAIRAN } \\
\text { KEP. BABAR }\end{array}$ & 1.123 & 5.02 & 391.4596072 & 3128922.952 & 348.5838 & 623291.4 \\
\hline N.17 & $\begin{array}{l}\text { PERAIRAN } \\
\text { KEP. } \\
\text { SERMATA - } \\
\text { KEP. LETI }\end{array}$ & 1.123 & 5.02 & 391.4596072 & 3128922.952 & 348.5838 & 623291.4 \\
\hline N.18 & $\begin{array}{l}\text { LAUT } \\
\text { ARAFURU } \\
\text { BAGIAN } \\
\text { BARAT }\end{array}$ & 1.123 & 5.6 & 391.4596072 & 6083920.282 & 348.5838 & 1086414 \\
\hline N.19 & $\begin{array}{l}\text { LAUT } \\
\text { ARAFURU } \\
\text { BAGIAN } \\
\text { TENGAH } \\
\end{array}$ & 1.123 & 5.6 & 391.4596072 & 6083920.282 & 348.5838 & 1086414 \\
\hline
\end{tabular}

Dari hasil perhitungan di atas, dapat di lihat bahwa pada kondisi minimum daya terkecil yang dapat dibangkitkan sebesar 348.5838 Watt, sementara daya terbesar yang dapat dihasilkan yaitu sebesar 623291.4 Watt.

\section{Potensi Kontribusi Aplikasi PLTGL Oscillating Water Column Pada Pemukiman Sederhana Tepi Pantai}

Dari hasil perhitungan di atas, dengan mengabaikan rugi-rugi daya yang terjadi efisiensi pada prototype sistem owc yang telah diterapkan di pantai sebesar $11.917 \%$ maka daya terkecil yang dapat dibangkitkan oleh sistem ini dalam keadaan minimum adalah sebesar:

348.5838 Watt x $11.917 \%=41.54 \mathrm{Watt}$

Dan dengan daya maksimum yang dapat dibangkitkan kurang lebih sebesar :

623291.4 Watt $x 11.917 \%=74277.6 \mathrm{Watt}$ 
Kemampuan membangkitkan daya sebesar 348.5838 Watt atau sekitar 348 Watt dapat digunakan untuk memberikan pasokan daya listrik baru bagi penggunaan listrik disekitar pantai.

\section{KESIMPULAN}

Dari hasil analisis dan perhitungan dapat disimpulkan :

1. Wilayah perairan pantai di Indonesia memiliki potensi yang bisa digunakan untuk menerapkan PLTGL sistem kolom air berosilasi.

2. Daya terkecil yang dapat dihasilkan adalah sebesar 348.5838 Watt

3. Daya terbesar yang dapat dihasilkan adalah sebesar 623291.4 Watt

4. Penerapan sistem Oscillating water column diwilayah perairan pantai dapat memberikan kontribusi daya listrik untuk rumah nelayan dengan efisiensi sebesar $11.971 \%$

\section{DAFTAR PUSTAKA}

1. Badan Meteorologi Klimatologi dan Geofisika, "Prakiraan Rata-rata Harian Tinggi Gelombang Laut di Wilayah Perairan Kendari Berlaku 24 Mei 2015.”

2. Budi Murdhani. "Analisis Rancang bangun Pembangkit Listrik Tenaga Gelombang Laut dengan Sistem Oscillating Water Column di Pantai Baron Yogyakarta.” Jakarta 2008.

3. http://www.dkp.go.id/index.php/ind/news/2623/berita-prakiraan-cuaca-maritim-untukpelayaran

4. Kadek Fendy Sutrisna "Pembangkit Listrik Masa Depan Indonesia." Laboratorium Konversi Energi Listrik Sekolah Teknik Elektro dan Informatika, Institut Teknologi Bandung, Februari, 2009.

5. Joseph Weisberg, Howard Parish. "Introduction Oceanography."

6. Anggraini, Lydia, Ardhi Bebi Laksono. "Pemodelan dan Analisa Struktur Mekanika pada Kontrol Sistem Adaptif End Effector dengan Dynamixel AX-18A Motor Servo." Journal of Mechanical Engineering and Mechatronics 3.1 (2019): 1-12. 